\title{
La búsqueda activa de un modelo de resiliencia como estrategia preventiva-adaptativa
}

\author{
Eugenio Ismael Rodríguez Castillo | arquitecto \\ URL de la contribución <www.iaph.es/revistaph/index.php/revistaph/article/view/4112>
}

\section{Introducción}

No es posible sustraer a las comunidades locales ni a su patrimonio natural y cultural de los riesgos de origen natural o antrópico a los que están expuestos, por razón de su ubicación geográfica y, además, no pueden eliminarse (UNESCO, 2007: 47) ni prevenirse por completo, adquiriendo el carácter de inevitables (UNESCO-WHC, 2010: 8), como son inevitables sus efectos sobre el patrimonio.

Estos efectos pueden alcanzar, con independencia de su origen o naturaleza, el rango de desastres, que es el término con el que se alude a situaciones de disrupción sobrevenida en el normal devenir de las comunidades, de manera que se trascienden sus propias capacidades de respuesta, provocando pérdidas de vidas humanas, daños materiales y medioambientales, y colapso económico (UNISDR, 2009: 9), abarcando el término un rango de eventos desde los fenómenos naturales a los actos deliberados de destrucción del patrimonio.

\section{Fenómenos naturales}

El cambio climático se ha constituido en una de las mayores amenazas que se ciernen sobre el patrimonio mundial (UNESCO-WHC, 2007: 3), con protagonismo culposo de la actividad antrópica, en relación con la aceleración y agudización de los procesos de degradación medioambiental.

Además, se evidencia un aumento significativo de la frecuencia y alcance de los desastres medioambientales (UNESCO, 2007: 13) que amenazan con causar un daño irreparable al patrimonio natural, en términos de reducción de la biodiversidad y alteración de ecosistemas.

La amenaza del cambio climático se cierne también sobre el patrimonio cultural, que ve agravados los pro- blemas inherentes de conservación por la transformación de las condiciones climáticas en las que tales bienes fueron creados o construidos, y afecta incluso a las comunidades locales, que ven alterado su modo de vida (UNESCO-WHC, 2007: 10).

La respuesta idónea es la búsqueda de la resiliencia necesaria (UNESCO-WHC, 2010: 2), en el sentido de proveerse de estrategias preventivas y mecanismos adaptativos que permitan, además de la salvaguarda del patrimonio, afrontar los cambios que se advierten y otros que vendrán, así como sus efectos, al tiempo que se preservan los valores universales excepcionales (VUE) que les han sido reconocidos y su autenticidad.

\section{Actos deliberados}

Las motivaciones de los actos deliberados de destrucción del patrimonio, especialmente por grupos extremistas en situaciones de conflicto, guardan relación con la destrucción del patrimonio como recurso eficaz de manipulación y propaganda (DANTI, 2015: 5), revestido de orgullosa impunidad (SAN MARTíN, 2016: 36) por las circunstancias y el contexto en que se han desarrollado, y que despiertan el rechazo inequívoco de la comunidad internacional, que no adquirió respaldo jurisprudencial hasta el año 2016, con la primera y ejemplar sentencia (SAN MARTíN, 2016: 31) de la Corte Penal Internacional, en relación con la destrucción violenta y deliberada de bienes culturales, por el caso de los crímenes de Ahmad al-Faqi al-Mahdi contra el patrimonio cultural de Tombuctú (Malí), en el año 2012.

Aun en tales casos consustancialmente graves, los actos contra el patrimonio revisten, en general, menos gravedad que los perpetrados contra las personas (SCPI ICC-01/12-01/15-171: 37), por lo que el estándar de gra- 
a debate Patrimonio, terrorismo y desastres naturales ¿Cómo prevenir y abordar los enormes daños al patrimonio cultural mundial?

| coordinan Francisco Javier López Morales, Francisco Vidargas

vedad criminal objetiva encuentra una justificación adicional esencial en la lesión de los VUE reconocidos en un patrimonio que está en íntima conexión con las comunidades locales y contra el que se ha atentado (SCPI ICC-01/12-01/15-171: 38), reforzando así una interpretación jurídica como crímenes de guerra (RCSNU S/ RES/2347: 4).

Por otra parte, en situaciones de conflicto con el concurso de grupos terroristas, se propende al saqueo continuado y sistemático del patrimonio cultural, y al tráfico ilícito de bienes culturales como fuente directa de financiación en un fenómeno global con múltiples ramificaciones delictivas y vinculado al crimen organizado (RCSNU S/RES/2347: 2).

Tal es el caso del desastre cultural de Irak y Siria -dramático este último-, donde el expolio de yacimientos arqueológicos ha sido un incidente cultural reiterado (DANTI, 2015: 1), de frecuencia diaria (CASANA, 2015: 151), y a escala industrial (DANTI, 2015: 4), que lastra cualquier estrategia de recuperación económica autónoma de las comunidades locales en el medio plazo, al tiempo que reduce el repertorio de elementos susceptibles de constituirse en un recurso de empoderamiento futuro, y allana el camino a la aculturación forzosa.

Al objetivo económico se le superpone así el cultural: la aniquilación de la diversidad y autenticidad de los pueblos sometidos. La gravedad de tales actos justificaría un posicionamiento abiertamente intervencionista de la UNESCO (SAN MARTÍN, 2016: 35), y un cambio de criterio en relación con la reconstrucción del patrimonio, inicialmente circunscrito a actuaciones de emergencia cultural en situaciones de conflicto, y cuya extrapolación indiscriminada se prevé de muy difícil justificación.

La solución vendrá por la vía de articular un marco de garantías que permita cesar el circuito del expolio cultural entre países de origen, tránsito y destino; y procurar a los sitios significados por razón de su patrimonio natural o cultural, la resiliencia necesaria para sobreponerse con éxito a la acción de los riesgos, peligros o amenazas que pudieran concurrir (UNESCO-WHC, 2010: 2), mediante una adecuada gestión del riesgo de desastres, que es un proceso sistemático, complejo, transversal y holístico que busca minimizar el impacto de riesgos, peligros y amenazas, así como reducir la probabilidad de que se produzca el temido desastre (UNISDR, 2009: 10), profundizando sobre la necesaria cultura preventiva.

\section{Resiliencia}

Así, la UNESCO persigue activamente un modelo ideal de resiliencia, poniendo el énfasis en: la gestión del riesgo de desastres (prevención); la trasferencia de conocimiento mediante la publicación de documentos auxiliares, manuales de referencia y casos de estudio con las mejores prácticas en relación con la protección y salvaguarda del patrimonio, la preservación de sus valores y autenticidad, etc. (información); la formación en los principios del respeto a la diversidad cultural y en materia de prevención, y el empoderamiento de las comunidades (educación); la sensibilización y estímulo de la necesaria implicación de la sociedad y sus órganos de representación y gobierno (concienciación); el papel activo de la comunidad internacional en la tutela, protección y salvaguarda del patrimonio (tutela); y la construcción progresiva de un marco legal universal, actualizado y capaz, con recursos económicos suficientes (garantía).

\section{BIBLIOGRAFÍA}

- CASANA, J. (2015) Satellite Imagery-Based Analysis of Archaeological Looting in Syria. Near Eastern Archaeology, vol. 78, n. ${ }^{\circ} 3,2015$, pp. 142-152

- DANTI, M. D. (2015) The Finance of Global Terrorism Through Cultural Property Crime in Syria and Northern Iraq [en línea] Washington DC: United States House of Representatives, Committee on Foreign Affairs, Subcommittee on Terrorism, Nonproliferation, and Trade, $2015<$ http://docs. house.gov/meetings/FA/FA18/20151117/104202/HHRG-114FA18-Wstate-DantiM-20151117.pdf> [Consulta: 28/12/2017]

- RESOLUCIÓN S/RES/2347 (2017), de 24 de marzo de 2017, del Consejo de Seguridad de las Naciones Unidas, sobre la destrucción y tráfico del patrimonio cultural por grupos terroristas y en situaciones de conflicto armado <http:// undocs.org/es/S/RES/2347(2017)> [Consulta: 27/12/2017] 
a debate Patrimonio, terrorismo y desastres naturales ¿Cómo prevenir y abordar los enormes daños al patrimonio cultural mundial?

| coordinan Francisco Javier López Morales, Francisco Vidargas

- SAN MARTín CALVO, M. (2016) La sanción penal internacional de los crímenes de guerra contra los bienes culturales. El asunto "Ahmad al-Mahdi". Revista Española de Relaciones Internacionales, n. ${ }^{\circ}$ 8, 2016, pp. 218-251

- SENTENCIA No ICC-01/12-01/15-171, de 27 de septiembre de 2016, de la Corte Penal Internacional, Sala VIII de Primera Instancia, Situación en la República de Mali en el Caso del Fiscal contra Ahmad al-Faqi al-Mahdi. Juicio Público y Sentencia [en línea], <https://www.icc-cpi.int/CourtRecords/ CR2016_07244.PDF> [Consulta: 27/12/2017]

- UNESCO (2007) Disaster preparedness and mitigation. UNESCO's role [en línea]. París: UNESCO, $2007<$ http:// unesdoc.unesco.org/images/0015/001504/150435e.pdf> [Consulta: 23/12/2017]

- UNESCO-WHC (2007) Climate Change and World Heritage. World Heritage Reports [en línea], n. ${ }^{\circ} 22,2007$ <http://whc. unesco.org/document/8874> [Consulta: 22/12/2017]

- UNESCO-WHC (2010) Managing Disaster Risks for World Heritage: World Heritage Resource Manual [en línea], París: UNESCO World Heritage Centre, $2010<\mathrm{http}$ ://whc.unesco.org/ uploads/activities/documents/activity-630-1.pdf> [Consulta: 22/12/2017]

- UNISDR (2009) Terminology on Disaster Risk Reduction [en línea]. Ginebra: United Nations International Strategy for Disaster Reduction, 2009 <http://www.unisdr.org/files/7817_ UNISDRTerminologyEnglish.pdf> [Consulta: 28/12/2017] 